\title{
EVALUASI USABILITY WEBSITE DINAS TENAGA KERJA DAN TRASMIGRASI KABUPATEN XYZ MENGGUNAKAN METODE THINK-ALOUD
}

\author{
Sri Rahayu Natasia, Putri Ayu Tri Ashshofiah, Yulistiana Eka Hartanti, Jamil Muhammad \\ Program Studi Sistem Informasi, Institut Teknologi Kalimantan \\ J1. Soekarno Hatta No.KM 15, Karang Joang, Kec. Balikpapan Utara, Kota Balikpapan, Kalimantan Timur \\ Natasia.ayu@lecturer.itk.ac.id, 10181033 @tudent.itk.ac.id, \\ 10181063estudent.itk.ac.id, 10181081@student.itk.ac.id
}

\begin{abstract}
Department of Labor and transmigration, xyz district developing a website-based information system that is expected to improve services to all the people of XYZ Regency. This study aims to determine the evaluation of the website of the Department of Labor and Transmigration of XYZ Regency so that it can be improved in order to form a website that can provide efficient and easy to understand information. This study uses the Think aloud method by providing 10 task scenarios for website testing to 8 respondents. Retrieval of respondent data is based on body posture and speech pointed to by the respondent when carrying out usability analysis. From the results of the task scenario testing, there were $62.5 \%$ of respondents who could do task 10 and as many as $87.5 \%$ of respondents who could do task 7 . And there are 6 negative responses. In addition, respondents were also asked to provide suggestions for improvements (if any). Recommendations for improving the website of the XYZ Regency Department of Labor and Transmigration Office include improving the header and footer, adding a search feature, tidying up fonts and text and making button improvements to make it easier for users to access and make the gallery folder look more attractive.
\end{abstract}

Keywords -Department of Labor and Transmigration of XYZ Regency, Evaluation, Task scenario, Website

Abstrak - Dinas Tenaga Kerja dan Transmigrasi Kabupaten XYZ mengembangkan sistem informasi berbasis website yang diharapkan mampu meningkatkan pelayanan kepada seluruh masyarakat Kabupaten XYZ. Penelitian ini bertujuan untuk mengetahui evaluasi website Dinas Tenaga Kerja dan Transmigrasi Kabupaten XYZ sehingga dapat diperbaiki guna terbentuknya website yang dapat menyajikan informasi yang efisien dan mudah dipahami. Penelitian ini menggunakan metode Think aloud dengan memberikan 10 task scenario pengujian website kepada 8 orang responden. Pengambilan data responden berdasarkan perilaku serta ucapan yang di tunjukkan oleh responden pada saat melaksanakan pengujian usability. Dari hasil pengujian task scenario terdapat sebanyak $62,5 \%$ responden yang dapat mengerjakan task 10 dan sebanyak 87,5\% responden yang dapat mengerjakan task 7. Serta terdapat sebanyak 6 respon negatif. Selain itu, responden juga di minta untuk memberikan saran perbaikan (jika ada). Rekomendasi perbaikan website Dinas Tenaga Kerja dan Transmigrasi Kabupaten $\mathrm{XYZ}$ yaitu perbaikan pada header dan footer, menambahkan fitur search, merapikan font dan text dan melakukan perbaikan button agar lebih di jangkau user serta membuat tampilan folder galeri menjadi lebih menarik

Kata Kunci - Dinas Tenaga Kerja dan Transmigrasi Kabupaten XYZ, Evaluasi, Task scenario, Website

\section{PENDAHULUAN}

Instruksi Presiden Nomor 3 tahun 2003 tentang Kebijakan dan Strategi Nasional Pengembangan EGovernment yang mengamanatkan setiap lembaga negara untuk membangun website guna mengembangkan e-government sebagai upaya untuk penyelenggaraan pemerintahan dalam melayanin masyarakat umum secara efektif dan efisien maka digunakan teknologi berbasis elektronik [1]. Berdasarkan Instruksi Presiden tersebut, Disnakertrans Kabupaten XYZ mengembangkan sistem informasi berbasis website dengan alamat situs disnakertrans.XYZkab.go.id. Oleh karena itu, website
Disnakertrans Kabupaten XYZ diharapkan dapat meningkatkan pelayanan kepada seluruh masyarakat Kabupaten XYZ. Disnakertransmerupakan instansi pemerintah yang memberikan informasi mengenai pencarian tenaga kerja dan lowongan kerja serta transmigrasi penduduk [2].

Pengembangan sistem informasi berbasis website tidak semudah yang dipikirkan karena penyampaian informasi melalui website haruslah didesain dengan baik agar mudah dipahami oleh pengguna sehingga website yang telah dikembangkan dapat diterima oleh masyarakat [3]. Karena itulah evaluasi usability website Disnakertrans Kabupaten XYZ sangat diperlukan agar dapat mengetahui kelemahan yang 
terdapat di website Disnakertrans Kabupaten XYZ sehingga dapat diperbaiki guna terbentuknya website yang dapat menyajikan informasi yang efisien dan mudah dipahami. Evaluasi usability website dapat dilakukan dapat menggunakan beberapa metode, salah satu metodenya yaitu think aloud. Metode think aloud merupakan pengujian usability situs website yang memiliki sifat praktis dengan cara menguraikan hasil pengamatan evaluasi secara nyata (real-life) dengan menyajikan informasi lengkap pada saat proses evaluasi usability berlangsung [4].

Tujuan dari penelitian ini adalah peneliti dapat memberikan hasil evaluasi usability website sebagai bahan perbaikan pada website Disnakertrans Kabupaten XYZ agar dapat menjadi lebih baik lagi dari sebelumnya sehingga website website Disnakertrans Kabupaten XYZ dapat menyajikan informasi yang efisien dan mudah dipahami bagi pengguna.

\section{A. Usability}

Usability memiliki arti secara umum berarti dapat digunakan dengan baik yang berasal dari kata Usable [5]. Usability merupakan suatu kualitas atribut yang dapat mengukur seberapa mudah user interface tersebut digunakan [6]. Sedangkan menurut ISO 9241-11 usability merupakan tingkatan produk yang dapat digunakan oleh pengguna dalam mencapai tujuannya dengan cara yang lebih efektif, efisien, dan memuaskan dalam lingkup penggunaannya. Sesuatu yang dapat dikatakan berguna dengan baik apabila dapat memberikan manfaat dan kepuasan kepada pengguna dengan cara menghilangkan atau meminimalkan kegagalan dalam penggunaanya. Suatu website dapat disebut mudah digunakan/usable jika fungsi-fungsi yang dimiliki dapat dijalankan secara efektif, efisien, dan memuaskan [7].

Usability memiliki tiga (tiga) faktor utama :

a. Learnbility yaitu keleluasaan pengguna dalam melakukan interaksi secara efektif dan mencapai kinerja yang optimal pada sistem yang digunakan.

b. Fleksibility yaitu cara-cara yang memungkinkan pengguna dan sistem bertukar informasi sehingga pengguna tidak terpatok pada satu pola dialog.

c. Robustness adalah kemampuan metode analisis untuk memvalidasi. Pengguna disediakan dengan berbagai tingkatan dukungan untuk mencapai tujuannya. Artinya bila salah satu cara yang ditempuh gagal maka terdapat metode atau opsi lain untuk mencapai tujuan tersebut.

Berdasarkan definisi diatas usability dapat diukur berdasarkan komponen berikut [6] :

a. Kemudahan (learnability) didefinisikan seberapa mudah sistem yang dikembangkan dapat dijalankan sesuai dengan keinginan oleh penggun.

b. Efisiensi (efficiency) didefinisikan sebagai aspek yang dapat mengukur pencapaian akurasi dan keseluruhan tujuan.

c. Mudah diingat (memorability) didefinisikan sebagai seberapa besar kemampuan pengguna dapat mempertahankan ingatannya untuk mengingat peletakkan menu yang selalu tetap.

d. Kesalahan dan keamanan (errors) didefinisikan berapa banyak kesalahan apa saja yang dilakukan oleh pengguna seperti ketidaksesuaian dengan pikiran pengguna dengan apa yang sebenarnya disajikan oleh sistem.

e. Kepuasan (satisfaction) didefinisikan sebagai kebebasan dari ketidaknyamanan serta sikap positif pengguna terhadap penggunaan suatu produk.

\section{B. Usability Testing}

Usability testing merupakan metode yang digunakan dalam mengevaluasi aspek usability pada sebuah produk dengan mengujinya langsung kepada pengguna. Tujuan dari dilaksanakannya Usability testing yaitu untuk mengidentifikasi masalah ketergantungan pengguna dalam hal kemudahan, efisiensi serta kepuasaan [8]. Usability testing, dilaksanakan dengan memberikan task yang harus diselesaikan oleh pengguna, sementara pengamat akan melihat, mendengar dan mencatat hasil evaluasi dari penggiina melalui task yang diberikan.

Usability testing merupakan kegiatan untuk mendapatkan respon dari pengguna yang dilakukan secara iteratif. Usability testing dapat digunakan dengan cara memilih pengguna berdasarkan kriteria, menentukan fungsi, membuat task, memastikan lama waktu usabiliy testing berlangsung, melakukan usability testing, merekam atau mencatat hasil usability testing untuk melakukan analisa data, dan terakhir memberikan rekomendasi perbaikan untuk sistem kedepannya [9]. Pengukuran usability dilakukan untuk menilai apakah suatu aplikasi dapat berinteraksi serta berjalan baik dengan pengguna [10]

\section{Think Aloud}

Menurut Panayiotis Zaphiris dalam bukunya yang berjudul "Human Computer Interaction Research in Web Design and Evaluation" bahwa metode evaluasi usability berfokus pada pengguna yang meliputi Usability Testing, Usability Inspection, Usability Inquiry, dan Usability Model / Metricsbased. Setiap metode memiliki beberapa teknik yang dapat digunakan untuk melakukan evaluasi usability. Terdapat 10 teknik metode Usability Testing yang dapat digunakan peneliti untuk melakukan Evaluasi usability meliputi Restrospective Testing, Thinking-Aloud Protocol, Question-Asking Protocol, Teaching Method, Performance Measurement, Eye Tracking, Remote Testing, Shadowing Method, Coaching Method, dan Co-Discovery Learning [8].

Think Aloud merupakan metode pengujian yang melibatkan end user untuk melakukan verbalisasi secara berkelanjutan terhadap apa yang dipikirkan pengguna pada saat menggunakan sistem. Untuk melakukan pengamatan terhadap interprestasi pada bagian interface yang sedang bermasalah maka dilakukan verbalisasi [11]. Verbalisasi dilakukan 
dengan cara merekam seluruh komentar yang dipikirkan oleh pengguna sehingga poin-poin penting pada saat proses analisa tidak terlewatkan. Keluaran dari metode ini berupa protokol verbal dan masalah usability pada tahap tertentu disiklus interaksi pengguna [12]. Metode think-aloud menjelaskan peninjauan situs web berdasarkan hasil evaluasi usability secara nyata yang ditampilkan dengan informasi lengkap pada saat proses evaluasi usability berlangsung [4].

\section{METODE PENELITIAN}

Penelitian Evaluasi Website Disnakertrans Kabupaten XYZ dilakukan menggunakan Metode Think aloud dengan tahapan penelitian sebagaimana Pada Gambar 1.
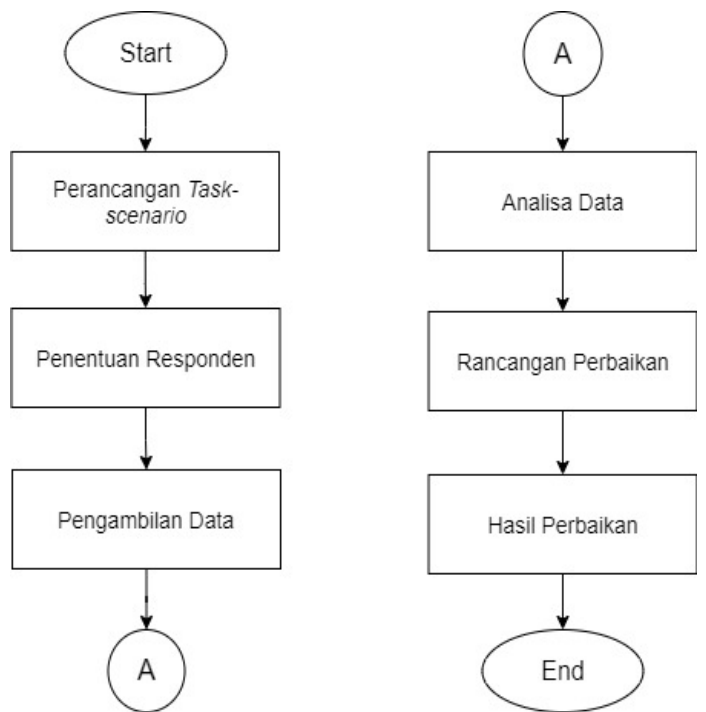

Gambar 1 Diagram Alur Penelitian

1. Perancangan Task-Scenario

Tahap penelitian ini melakukan perancangan untuk task-scenario yang akan diberikan kepada responden. Task scenario berfungsi sebagai bahan penguji antarmuka pada Disnakertrans Kabupaten XYZ kepada responden. Task yang dibuat sebanyak 10 (sepuluh) task pada menu yang berbeda pada website Disnakertrans Kabupaten XYZ.

\section{Penentuan Responden}

Tahap ini dilakukan untuk menentukan kriteria responden yang dibutuhkan dalam proses pengambilan data diperlukan delapan sampai sepuluh orang responden saja, karena menurut Ericsson dan Simon (1993) jumlah tersebut telah mencukupi dalam memahami perilaku reponden yang telah diberikan task untuk melakukan evaluasi [4]. Pada penelitian ini dibutuhkan yaitu 8 (delapan) responden untuk pengambilan sample secara acak dengan kriteria responden miniman berumur 17 tahun dan maksimal berumur 35 tahun serta memiliki kemampuan literasi internet (internet literacy skill), mampu mengoperasikan internet melalui device, dan terbiasa dalam penggunaan teknologi komputer.

\section{Pengambilan Data}

Tahapan berikutnya yang akan dilakukan adalah Pengambilan Data. Dalam metode think-aloud pengambilan data responden didasarkan pada perilaku serta ucapan yang di tunjukkan oleh responden pada saat melaksanakan analisis usability. Pada penelitian ini data dikumpulkan melalui responden dengan memberikan 10 (sepuluh) task lalu memberikan maksimal pengerjaan 2 (dua) menit setiap task-nya. Kegiatan pengerjaan task yang diberikan akan di rekam dan di catat waktu pengerjaan pada setiap responden. Analisis yang dilakukan oleh responden pada website Disnakertrans Kabupaten XYZ berdasarkan pada skenario yang telah peneliti tetapkan.

\section{Analisa Data}

Tahap ini dilakukan analisis data berdasarkan hasil evaluasi yang telah dilaksanakan oleh responden. Data yang di peroleh dari responden berupa hasil dari pengerjaan task-scenario seperti total waktu yang di dapatkan ketika responden mengerjakan sebuah task, jumlah total task yang dapat di kerjakan oleh responden dan juga pendapat responden ketika selesai mengerjakan task. Jadi responden akan diminta untuk mengemukakan pendapat positif, pendapat negatif dan juga saran evaluasi (jika ada) pada webiste Disnakertrans Kabupaten XYZ yang akan mencerminkan tingkat kepuasan responden terhadap website Disnakertrans Kabupaten XYZ. Tanggapan positif merupakan rangkaian kata atau kalimat yang mengekspresikan perasaan puas, takjub, bahagia dan sebagainya pada saat mengakses situs website Disnakertrans Kabupaten XYZ. Sedangkan tanggapan negatif merupakan ungkapan yang mengekpresikan perasaan kecewa dan tidak suka. Seluruh data yang didapatkan dari hasil pengerjaan task-scenario akan di evaluasi untuk mengetahui hasil data yang diinginkan.

\section{Rancangan Perbaikan}

Setelah didapatkan hasil analisis data, maka langkah selanjutnya adalah membuat rancangan perbaikan berdasarkan penilaian dan hasil analisis data responden. Pada tahap ini dilakukan rancangan perbaikan website Disnakertrans Kabupaten XYZ dengan melakukan pembuatan design mockup wireframe.

\section{Hasil Perbaikan}

Tahapan ini merupakan tahapan akhir dimana akhir dari evaluasi pada web Disnakertrans Kabupaten XYZ berupa tampilan prototype/ website static.

\section{HASIL DAN PEMBAHASAN}

\section{A. Perancangan Task Scenario}

Pengujian pengguna dilakukan dengan cara meminta responden untuk menjalankan task scenario 
yang telah disiapkan. Task scenario berfungsi sebagai bahan penguji antarmuka pada Disnakertrans Kabupaten XYZ. Adapun task scenario yang telah dirancang dan harus dijalankan oleh responden ditujukan pada Tabel 1 berikut.

Tabel 1. Task Scenario

\begin{tabular}{|c|l|}
\hline No & \multicolumn{1}{|c|}{ Task Scenario } \\
\hline T1 & $\begin{array}{l}\text { Mengakses website Disnakertrans XYZ } \\
\text { dengan alamat situs } \\
\text { disnakertrans.XYZkab.go.id }\end{array}$ \\
\hline T2 & $\begin{array}{l}\text { Mencari visi misi tujuan serta fungsi dari } \\
\text { Disnakertrans XYZ }\end{array}$ \\
\hline T3 & $\begin{array}{l}\text { Mengakses halaman sekretariat dan Bidang } \\
\text { Penempatan dan Peluasan Kerja }\end{array}$ \\
\hline T4 & $\begin{array}{l}\text { Mengunduh Dokumen Perjanjian Kerja } \\
\text { Terbaru }\end{array}$ \\
\hline T5 & $\begin{array}{l}\text { Mencari informasi lowongan kerja PT. Satu } \\
\text { Sembilan Delapan }\end{array}$ \\
\hline T6 & $\begin{array}{l}\text { Mengunduh Dokumen UU RI No.13 Tahun } \\
\text { 2013 Tentang Ketenagakerjaan. }\end{array}$ \\
\hline T7 & $\begin{array}{l}\text { Mencari informasi contact dari } \\
\text { Disnakertrans XYZ }\end{array}$ \\
\hline T8 & Mencari dokumentasi kunjungan dewan \\
\hline T9 & $\begin{array}{l}\text { Mengakses Bursa Kerja Online XYZ } \\
\text { melalui website Disnakertrans }\end{array}$ \\
\hline T10 & Mencetak rencana program kegiatan \\
\hline
\end{tabular}

Task scenario yang telah dirancang berjumlah 10 (sepuluh) task, dimana task tersebut diambil dari menu yang berbeda pada website Disnakertrans Kabupaten $\mathrm{XYZ}$.

\section{B. Penentuan Responden}

Pengujian usability pada website Disnakertrans Kabupaten XYZ ini dilakukan kepada 8 (delapan) responden dengan rentang umur 19 sampai 25 tahun, dimana responden yang menjalankan seluruh task yang diberikan memiliki kemampuan literasi internet (internet literacy skill), mampu mengoperasikan internet melalui device, dan terbiasa dalam penggunaan teknologi komputer.

\section{Pengambilan Data}

Setelah menyusun task scenario maka langkah selanjutnya yaitu pengambilan data dengan cara melakukan wawancara kepada responden untuk melakukan pengujian terhadap website Disnakertrans Kabupaten XYZ. Pengujian dilakukan oleh responden dengan cara menjalankan task yang diberikan. Pada saat pengujian berlangsung, pewawancara akan merekam waktu responden dalam menjalankan seluruh task yang diberikan dan mencatat semua perilaku yang dilakukan oleh responden selama pengujian berlangsung. Adapun rekapitulasi waktu pelaksanaan pengujian website Disnakertrans Kabupaten XYZ setiap responden ditujukan pada Tabel 2 berikut.

Tabel 2. Waktu Pengujian Responden (s)

\begin{tabular}{|c|c|c|c|c|c|c|c|c|c|c|}
\hline & $\mathbf{T}$ & $\mathbf{T}$ & $\mathbf{T}$ & $\mathbf{T}$ & $\mathbf{T}$ & $\mathbf{T}$ & $\mathbf{T}$ & $\mathbf{T}$ & $\mathbf{T}$ & $\mathbf{T}$ \\
$\mathbf{1}$ & $\mathbf{2}$ & $\mathbf{3}$ & $\mathbf{4}$ & $\mathbf{5}$ & $\mathbf{6}$ & $\mathbf{7}$ & $\mathbf{8}$ & $\mathbf{9}$ & $\mathbf{1 0}$ \\
\hline $\mathbf{R}$ & $0:$ & $0:$ & $0:$ & $0:$ & $0:$ & $0:$ & $0:$ & $0:$ & $0:$ & $\mathrm{X}$ \\
$\mathbf{1}$ & 02 & 15 & 15 & 16 & 30 & 27 & 06 & 05 & 02 & \\
\hline $\mathbf{R}$ & $0:$ & $0:$ & $0:$ & $0:$ & $2:$ & $2:$ & $1:$ & $0:$ & $0:$ & $1:$ \\
$\mathbf{2}$ & 02 & 18 & 08 & 13 & 00 & 00 & 05 & 10 & 02 & 15 \\
\hline $\mathbf{R}$ & $0:$ & $0:$ & $0:$ & $0:$ & $0:$ & $0:$ & $0:$ & $0:$ & $0:$ & $0:$ \\
$\mathbf{3}$ & 02 & 20 & 30 & 08 & 11 & 07 & 01 & 03 & 02 & 36 \\
\hline $\mathbf{R}$ & $0:$ & $0:$ & $0:$ & $0:$ & $0:$ & $0:$ & $1:$ & $0:$ & $0:$ & $\mathrm{X}$ \\
$\mathbf{4}$ & 02 & 40 & 30 & 14 & 21 & 11 & 30 & 05 & 05 & \\
\hline $\mathbf{R}$ & $0:$ & $0:$ & $0:$ & $0:$ & $0:$ & $0:$ & $0:$ & $0:$ & $0:$ & $0:$ \\
$\mathbf{5}$ & 02 & 25 & 19 & 08 & 23 & 17 & 36 & 03 & 24 & 34 \\
\hline $\mathbf{R}$ & $0:$ & $0:$ & $0:$ & $0:$ & $0:$ & $0:$ & $0:$ & $0:$ & $0:$ & $0:$ \\
$\mathbf{6}$ & 02 & 16 & 25 & 32 & 15 & 31 & 03 & 07 & 02 & 33 \\
\hline $\mathbf{R}$ & $0:$ & $0:$ & $0:$ & $0:$ & $0:$ & $0:$ & $0:$ & $0:$ & $0:$ & $0:$ \\
$\mathbf{7}$ & 02 & 15 & 14 & 14 & 44 & 16 & 03 & 06 & 05 & 32 \\
\hline $\mathbf{R}$ & $0:$ & $0:$ & $0:$ & $0:$ & $2:$ & $2:$ & & $0:$ & $0:$ & $\mathrm{X}$ \\
$\mathbf{8}$ & 02 & 17 & 35 & 17 & 00 & 00 & $\mathrm{X}$ & 10 & 26 & $\mathrm{X}$ \\
\hline
\end{tabular}

Adapun rekapitulasi keberhasilan responden menjalankan task yang diberikan pada saat pengujian website Disnakertrans Kabupaten XYZ dapat dilihat pada Tabel 3 berikut.

Tabel 3. Hasil Pengujian Task Scenario

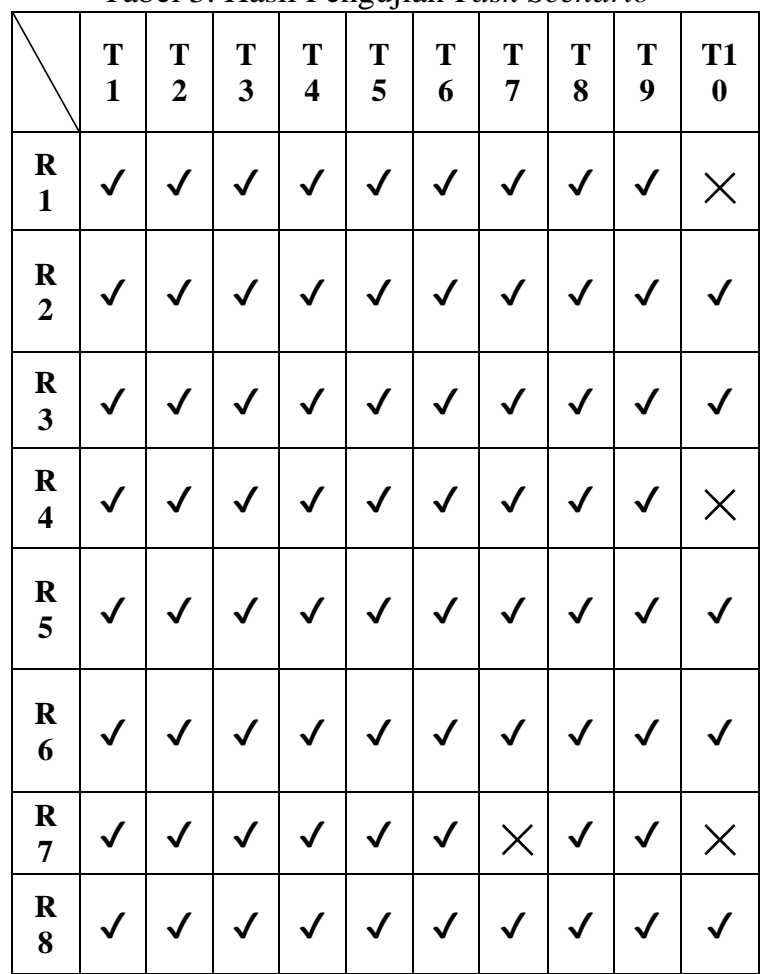

Dari hasil pengujian task scenario yang dijalankan oleh responden yang berdasarkan pada tabel 3 dapat disimpulkan bahwa dari 8 (delapan) responden terdapat 3 responden yang tidak dapat melaksanakan seluruh task yang diberikan sedangkan 5 responden lainnya dapat melaksanakan seluruh task yang diberikan. Task yang tidak dapat dilaksanakan oleh 3 responden yaitu task 7 yaitu mencari informasi contact dari Disnakertrans Kabupaten XYZ dan task 10 yaitu mencetak rencana program kegiatan. 


\section{Analisa Data}

Berdasarkan evaluasi website Disnakertrans Kabupaten XYZ yang didapatkan melalui pengujian pengguna dengan menjalankan seluruh task yang diberikan maka dihasilkan rekapitulasi data tanggapan positif yang dapat dilihat pada Tabel 4 berikut.

Tabel 4 Tanggapan Positif Responden

\begin{tabular}{|c|c|}
\hline Task & Tanggapan Positif \\
\hline 1 & $\begin{array}{l}\text { Terdapat } 100 \% \text { responden }(\mathrm{R} 1, \mathrm{R} 2, \mathrm{R} 3, \mathrm{R} 4 \text {, } \\
\mathrm{R} 5, \mathrm{R} 6, \mathrm{R} 7 \text { dan } \mathrm{R} 8) \text { dapat mencari visi misi, } \\
\text { tujuan dan fungsi dengan mudah dan tidak } \\
\text { membutuhkan waktu yang lama karena sub } \\
\text { menu yang ditampilkan jelas }\end{array}$ \\
\hline 2 & $\begin{array}{l}\text { Terdapat } 100 \% \text { responden }(\mathrm{R} 1, \mathrm{R} 2, \mathrm{R} 3, \mathrm{R} 4 \text {, } \\
\mathrm{R} 5, \mathrm{R} 6, \mathrm{R} 7 \text { dan } \mathrm{R} 8) \text { dapat mencari visi misi, } \\
\text { tujuan dan fungsi dengan mudah dan tidak } \\
\text { membutuhkan waktu yang lama karena sub } \\
\text { menu yang sudah tertampil dengan jelas }\end{array}$ \\
\hline 3 & $\begin{array}{l}\text { Terdapat } 100 \% \text { responden }(\mathrm{R} 1, \mathrm{R} 2, \mathrm{R} 3, \mathrm{R} 4 \text {, } \\
\mathrm{R} 5, \mathrm{R} 6, \mathrm{R} 7 \text { dan } \mathrm{R} 8) \text { dapat mengakses } \\
\text { halaman sekretariat dan bidang penempatan } \\
\text { dan peluasan kerja karena sub menu yang } \\
\text { tertampil dengan jelas }\end{array}$ \\
\hline 4 & $\begin{array}{l}\text { Terdapat } 100 \% \text { responden (R1, R2, R3, R4, } \\
\text { R5, R6, R7 dan R8) dapat mengunduh } \\
\text { dokumen perjanjian kerja terbaru karena } \\
\text { sub menu yang ditampilkan jelas serta } \\
\text { dokumen yang mudah diakses }\end{array}$ \\
\hline 5 & $\begin{array}{l}\text { Terdapat } 100 \% \text { responden (R1, R2, R3, R4, } \\
\text { R5, R6, R7 dan R8) dapat mencari } \\
\text { informasi lowongan kerja PT. Satu } \\
\text { Sembilan Delapan karena sub menu yang } \\
\text { ditampilkan jelas serta dokumen yang } \\
\text { mudah diakses }\end{array}$ \\
\hline 6 & $\begin{array}{l}\text { Terdapat } 100 \% \text { responden (R1, R2, R3, R4, } \\
\text { R5, R6, R7 dan R8) dapat mengunduh } \\
\text { dokumen UUD RI No } 13 \text { Tahun } 2013 \\
\text { tentang Ketenagakerjaan karena sub menu } \\
\text { yang ditampilkan jelas serta dokumen yang } \\
\text { mudah diakses }\end{array}$ \\
\hline 7 & $\begin{array}{l}\text { Terdapat } 87,5 \% \text { responden }(\mathrm{R} 1, \mathrm{R} 2, \mathrm{R} 3 \text {, } \\
\mathrm{R} 4, \mathrm{R} 5, \mathrm{R} 6 \text { dan R8) dapat mencari } \\
\text { informasi kontak dari Disnakertrans XYZ } \\
\text { karena informasi kontak terdapat di header } \\
\text { website }\end{array}$ \\
\hline 8 & $\begin{array}{l}\text { Terdapat } 100 \% \text { responden }(\mathrm{R} 1, \mathrm{R} 2, \mathrm{R} 3, \mathrm{R} 4 \text {, } \\
\mathrm{R} 5, \mathrm{R} 6, \mathrm{R} 7 \text { dan } \mathrm{R} 8) \text { dapat mencari } \\
\text { dokumentasi kunjungan dewan karena sub } \\
\text { menu yang ditampilkan jelas dan mudah } \\
\text { diakses }\end{array}$ \\
\hline 9 & $\begin{array}{l}\text { Terdapat } 100 \% \text { responden }(\mathrm{R} 1, \mathrm{R} 2, \mathrm{R} 3, \mathrm{R} 4 \text {, } \\
\mathrm{R} 5, \mathrm{R} 6, \mathrm{R} 7 \text { dan } \mathrm{R} 8) \text { dapat mengakses Bursa } \\
\text { Kerja Online XYZ dengan mudah karena } \\
\text { sub menu yang ditampilkan jelas }\end{array}$ \\
\hline 10 & $\begin{array}{l}\text { Terdapat } 62,5 \% \text { responden }(\mathrm{R} 2, \mathrm{R} 3, \mathrm{R} 5, \mathrm{R} 6 \\
\text { dan } \mathrm{R} 8) \text { dapat menemukan icon mencetak } \\
\text { rencana program kegiatan }\end{array}$ \\
\hline
\end{tabular}

Berdasarkan Tabel 4 dapat disimpulkan bahwa dari 10 task yang telah diberikan, responden memberikan tanggapan positif yang berisi rangkaian kata atau kalimat yang mengekspresikan perasaan puas, takjub, bahagia dan sebagainya pada saat mengakses situs website Disnakertrans Kabupaten XYZ. Berikut tanggapan negatif dari responden yang dapat dilihat pada Tabel 5

Tabel 5. Tanggapan Negatif Responden

\begin{tabular}{|c|c|}
\hline Task & Tanggapan Negatif \\
\hline 1 & $\begin{array}{l}\text { Tidak terdapat tanggapan negatif pada saat } \\
\text { mengerjakan task ini }\end{array}$ \\
\hline 2 & $\begin{array}{l}\text { Tidak terdapat tanggapan negatif pada saat } \\
\text { mengerjakan task ini }\end{array}$ \\
\hline 3 & $\begin{array}{l}\text { R3 merasa bahwa halaman sekretariat } \\
\text { bersifat ambigu karena pada sub menu } \\
\text { sekretariat terdapat sub menu lagi } \\
\text { didalamnya padahal sub menu tersebut } \\
\text { tidak berisi informasi apapun. R4 merasa } \\
\text { bahwa tidak sesuainya nama submenu } \\
\text { dengan isi outline yang di tampilkan }\end{array}$ \\
\hline 4 & $\begin{array}{l}\text { Tidak terdapat tanggapan negatif pada saat } \\
\text { mengerjakan task ini }\end{array}$ \\
\hline 5 & $\begin{array}{l}\text { R1 dan R2 merasa sulit menemukan serta } \\
\text { membutuhkan waktu untuk mencari } \\
\text { dokumen. } \mathrm{R} 4 \text { merasa bahwa halaman task } \\
\text { ini terlihat tidak rapi }\end{array}$ \\
\hline 6 & $\begin{array}{l}\text { R2 dan R3 merasa membutuhkan waktu } \\
\text { dalam pencarian dokumen karena tidak } \\
\text { ditempatkan di satu sub menu khusus } \\
\text { dokumen }\end{array}$ \\
\hline 7 & $\begin{array}{l}\text { R2, R4, R5 dan R7 merasa membutuhkan } \\
\text { waktu untuk menemukan informasi kontak } \\
\text { dikarenakan penulisan font informasi } \\
\text { kontak terlalu kecil }\end{array}$ \\
\hline 8 & $\begin{array}{l}\text { R3, R4, R6 dan R8 merasa bahwa } \\
\text { dokumentasi pada sub menu galeri yang } \\
\text { diberikan tidak rapi dan memiliki icon yang } \\
\text { tidak jelas fungsinya }\end{array}$ \\
\hline 9 & $\begin{array}{l}\text { Tidak terdapat tanggapan negatif pada saat } \\
\text { mengerjakan task ini }\end{array}$ \\
\hline 10 & $\begin{array}{l}\mathrm{R} 1 \text {, R4 dan } \mathrm{R} 7 \text { tidak dapat menemukan icon } \\
\text { mencetak rencana program kegiatan karena } \\
\text { icon berukuran kecil serta terletak dibagian } \\
\text { bawah artikel dan aspek kurang teliti dari } \\
\text { responden }\end{array}$ \\
\hline
\end{tabular}

Berdasarkan Tabel 4 dapat disimpulkan bahwa dari 10 task yang telah diberikan, responden memberikan tanggapan negatif yang berisi ungkapan yang mengekpresikan perasaan kecewa dan tidak suka pada saat mengakses situs website Disnakertrans Kabupaten XYZ.

\section{E. Rancangan Perbaikan}

Setelah responden memberikan tanggapan positif dan negatif pada saat melaksanakan pengujian usability pada website Disnakertrans Kabupaten XYZ yang dapat 
dilihat pada Tabel 4 dan 5, responden juga memberikan saran evaluasi untuk website Disnakertrans Kabupaten XYZ sebagai bahan perbaikan bagi website Disnakertrans Kabupaten XYZ agar dapat menyajikan informasi yang efisien dan mudah dipahami bagi pengguna. Adapun saran evaluasi yang diberikan oleh responden dapat dilihat pada Tabel 6 berikut.

Tabel 6. Saran Evaluasi

\begin{tabular}{|c|l|}
\hline Task & \multicolumn{1}{|c|}{ Saran Evaluasi } \\
\hline 1 & $\begin{array}{l}\text { Tidak ada tanggapan rekomendasi pada } \\
\text { task ini }\end{array}$ \\
\hline 2 & $\begin{array}{l}\text { R1 dan R3 memberikan rekomendasi } \\
\text { penulisan perataan pada text seharusnya } \\
\text { dapat lebih konsisten }\end{array}$ \\
\hline 3 & $\begin{array}{l}\text { R4 memberikan rekomendasi agar nama } \\
\text { pada submenu dapat disesuaikan dengan } \\
\text { Outline yang ada }\end{array}$ \\
\hline 5 & $\begin{array}{l}\text { Tidak ada tanggapan rekomendasi pada } \\
\text { task ini }\end{array}$ \\
\hline 5 & $\begin{array}{l}\text { R4 memberikan rekomendasi agar pada } \\
\text { halaman lowongan kerja agar dibuat } \\
\text { tampilan yang lebih rapi }\end{array}$ \\
\hline 6 & $\begin{array}{l}\text { R3 memberikan rekomendasi pada task ini } \\
\text { agar dapat di gabung dengan menu } \\
\text { download }\end{array}$ \\
\hline 7 & $\begin{array}{l}\text { R2 Informasi kontak sebaiknya dibuatkan } \\
\text { fitur sendiri dan bisa menambahkan fitur } \\
\text { search. R4, R5 dan R7 memberikan } \\
\text { rekomendasi agar ukuran pada font } \\
\text { informasi kontak bisa lebih besar agar } \\
\text { mudah dilihat }\end{array}$ \\
\hline 10 & $\begin{array}{l}\text { R6 memberikan rekomendasi agar } \\
\text { menghapus tombol yang tidak diketahui } \\
\text { fungsinya pada fitur galeri dan merapikan } \\
\text { isi dari galeri. R2 dan R8 memberikan } \\
\text { rekomendasi agar susunan dokumentasi } \\
\text { menjadi foto lalu keterangan agar lebih rapi }\end{array}$ \\
\hline $\begin{array}{l}\text { Tidak ada tanggapan rekomendasi pada } \\
\text { task ini } \\
\text { task ini }\end{array}$ \\
\hline adak ada tanggapan rekomendasi pada \\
\hline
\end{tabular}

Berdasarkan saran evaluasi yang telah diberikan oleh responden yang dapat dilihat pada Tabel 6 dapat disimpulkan bahwa pada task 2, 3, 5, 6, 7 dan 8 mendapatkan saran evaluasi atau perbaikan dari responden. Oleh karena itu, dilakukan perancangan perbaikan website dengan membuat mockup wireframe menggunakan aplikasi Figma. Adapun mockup wireframe yang telah dirancang dapat dilihat pada gambar 2 sebagai berikut.

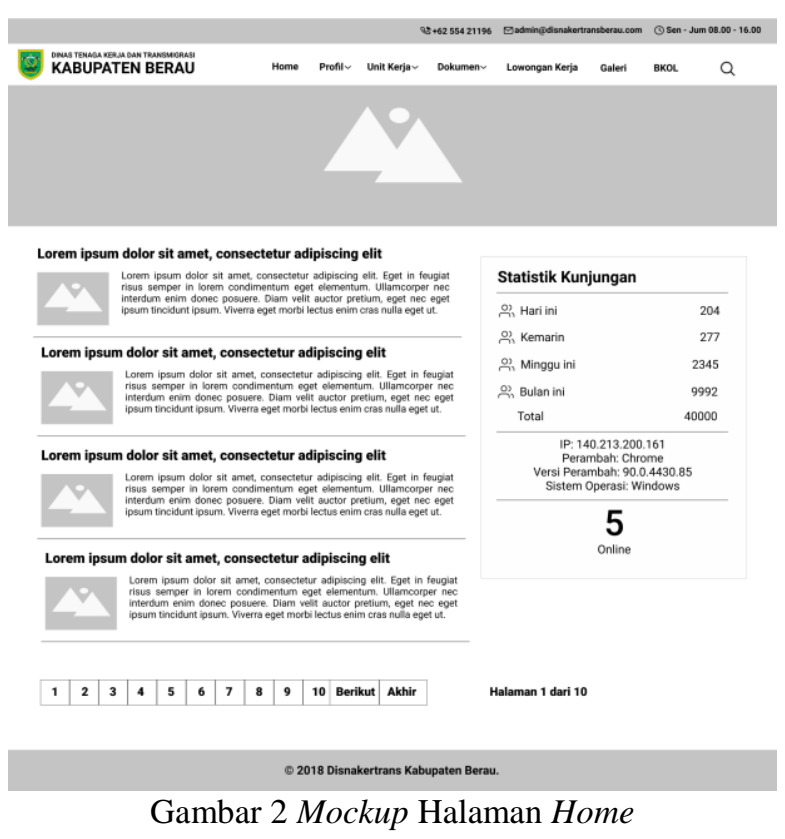

Pada halaman home dilakukan perbaikan pada header dan footer. Pada header terdapat informasi kontak dari Disnakertrans Kabupaten XYZ namun berukuran sangat kecil sehingga pengguna akan sedikit kesulitan untuk menemukan informasi kontak tersebut, maka dilakukan perbaikan dengan mengubah warna header dengan warna abu-abu muda serta memperbesar tulisan pada informasi kontak. Pada footer dilakukan perbaikan dengan mengubah warna menjadi abu-abu muda serta penulisan copyright diletakkan di tengah footer. Selain itu ditambahkan pula fitur search pada keselurahan halaman.

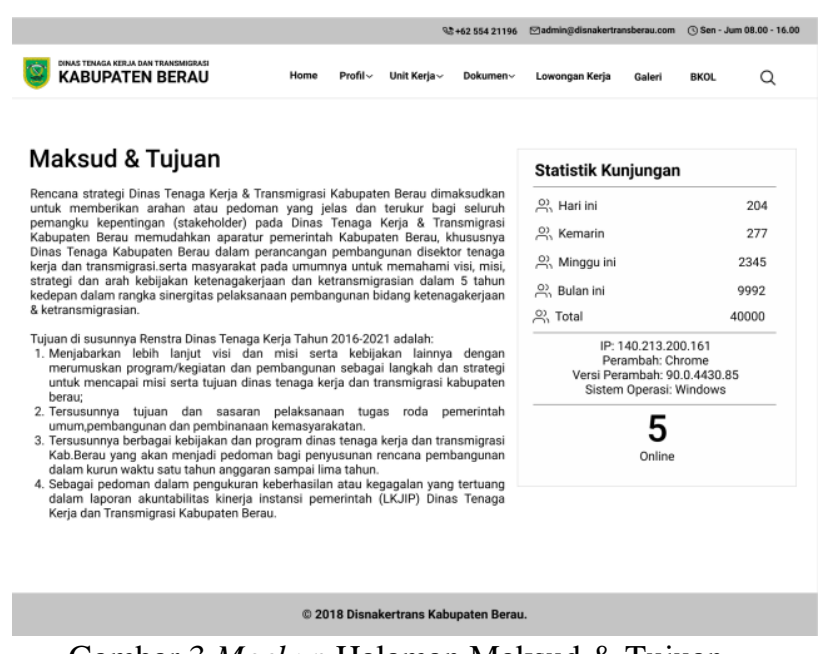

Gambar 3 Mockup Halaman Maksud \& Tujuan

Pada halaman maksud \& tujuan yang di tujukan pada gambar 3, dilakukan pengubahan font pada penulisan artikel di halaman tersebut. Evaluasi dilakukan karena font pada halaman ini tidak menggunakan font Roboto seperti pada halaman 
lainnya, sehingga dilakukan pengubahan font dari font Times New Roman menjadi font Roboto.

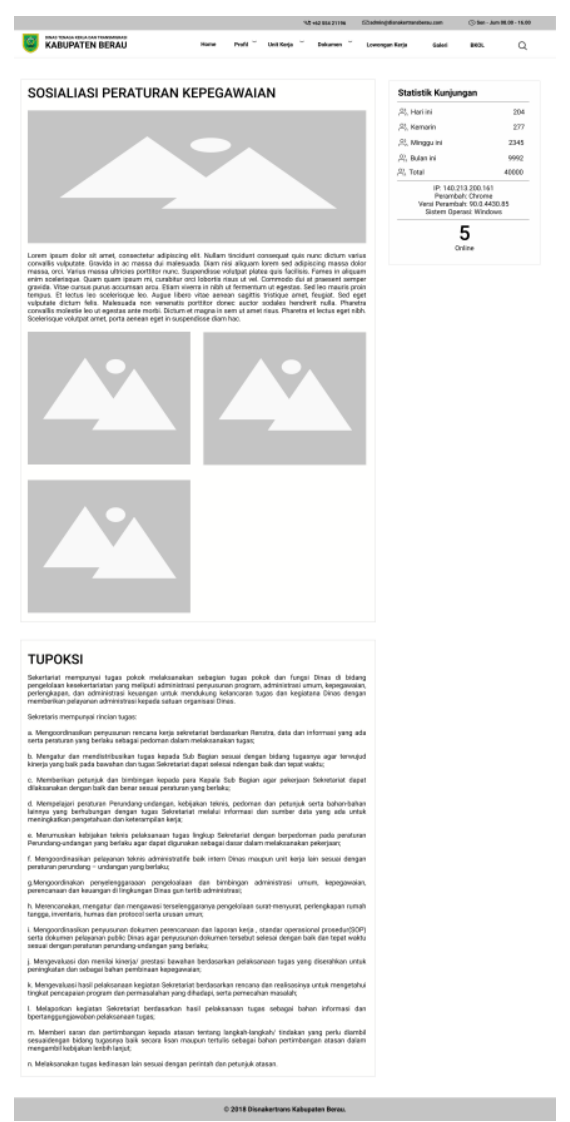

Gambar 4 Mockup Halaman Sosialisasi Peraturan Kepegawaian

Pada halaman sosialisasi peraturan yang di kepegawaian yang ditujukan pada gambar 4, dilakukan perbaikan pada paragraf penulisan artikel. Evaluasi atau perbaikan dilakukan karena penulisan artikel pada website Disnakertrans Kabupaten XYZ tidak rapi sehingga pengguna kurang nyaman pada saat membaca artikel yang ada pada halaman tersebut.

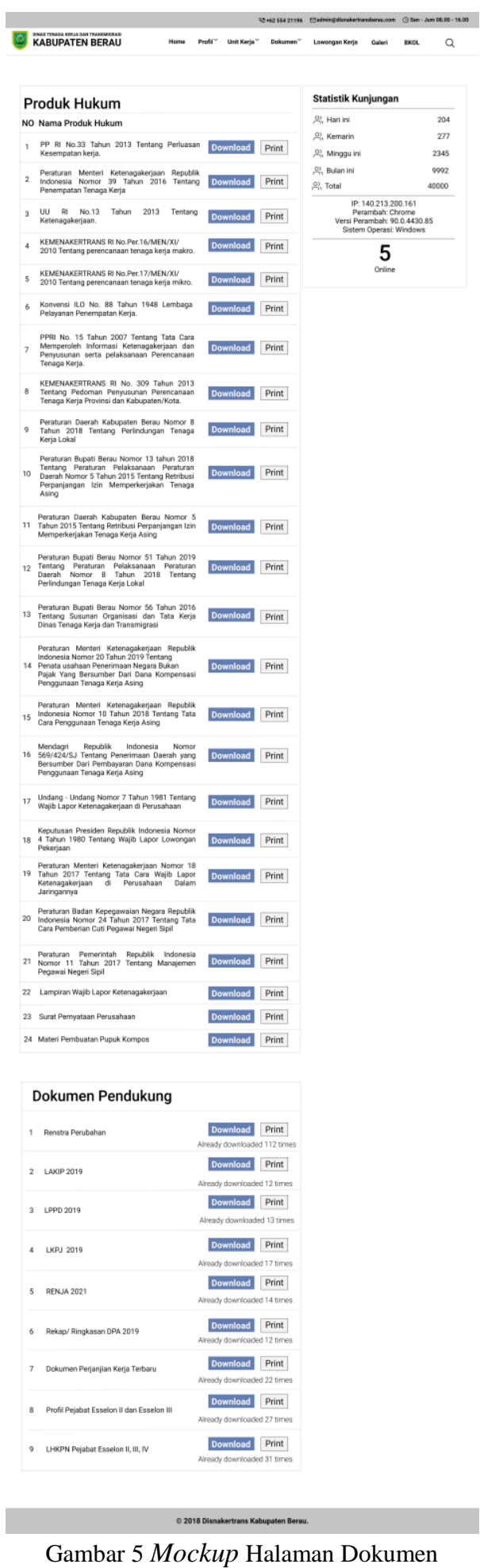

Halaman dokumen pada gambar 5, merupakan penggabungan dari halaman download dan halaman produk hukum. Penggabungan dilakukan karena menurut responden kedua halaman tersebut memiliki isi dan fungsi yang sama yaitu halaman tersebut hanya berisikan dokumen yang dapat diunduh serta di cetak saja. Berdasarkan saran evaluasi dari responden maka dilakukan penggabungan dokumen pada halaman 
download dan dokumen pada halaman produk hukum karena memiliki fungsi dan isi yang sama sehingga pengguna tidak perlu ke halaman lain untuk melakukan pengunduhan dan pencetakkan dokumen yang disediakan pada website.

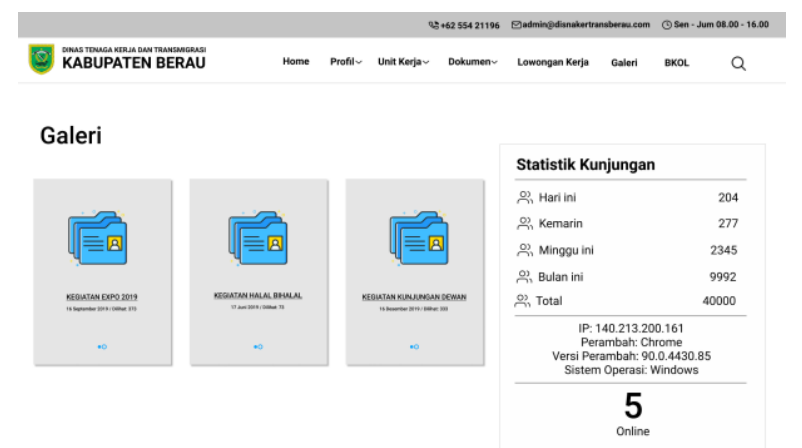

Gambar 6 Mockup Halaman Galeri

Halaman galeri pada gambar 6, dilakukan perbaikan dengan merapikan folder galeri serta memberikan keterangan disetiap foto pada folder galeri yang tersedia.

\section{F. Hasil Perbaikan}

Setelah dilakukan perancangan mockup wireframe maka langkah selanjutnya yaitu pembuatan prototype dari website Disnakertrans Kabupaten XYZ menggunakan aplikasi Figma. Adapun prototype dari Disnakertrans Kabupaten XYZ yang telah dibuat berdasarkan evaluasi dari responden dapat dilihat pada gambar 7 hingga gambar 11 sebagai berikut.

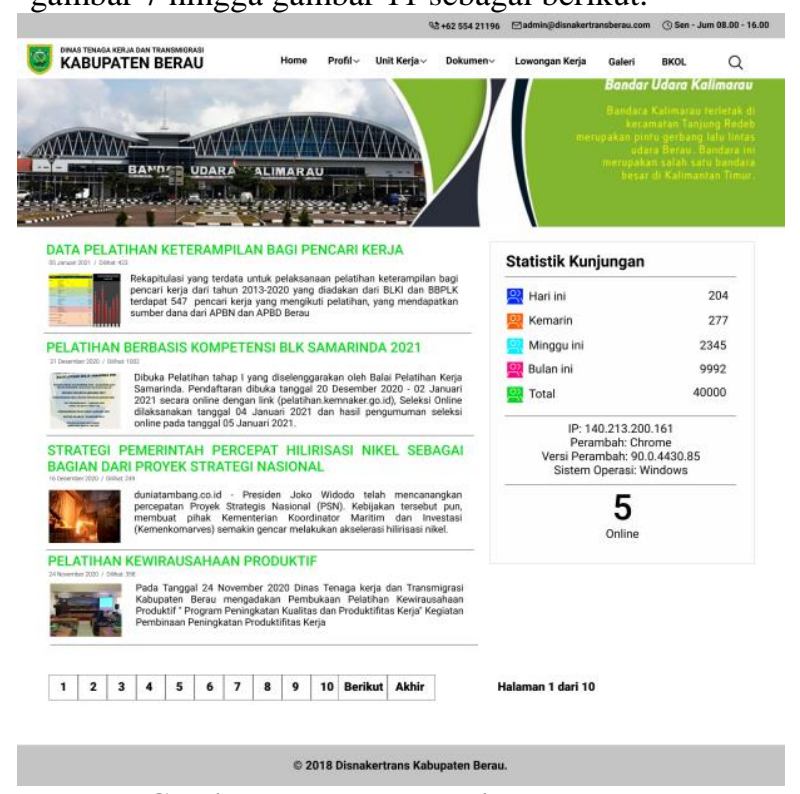

Gambar 7 Prototype Halaman Home
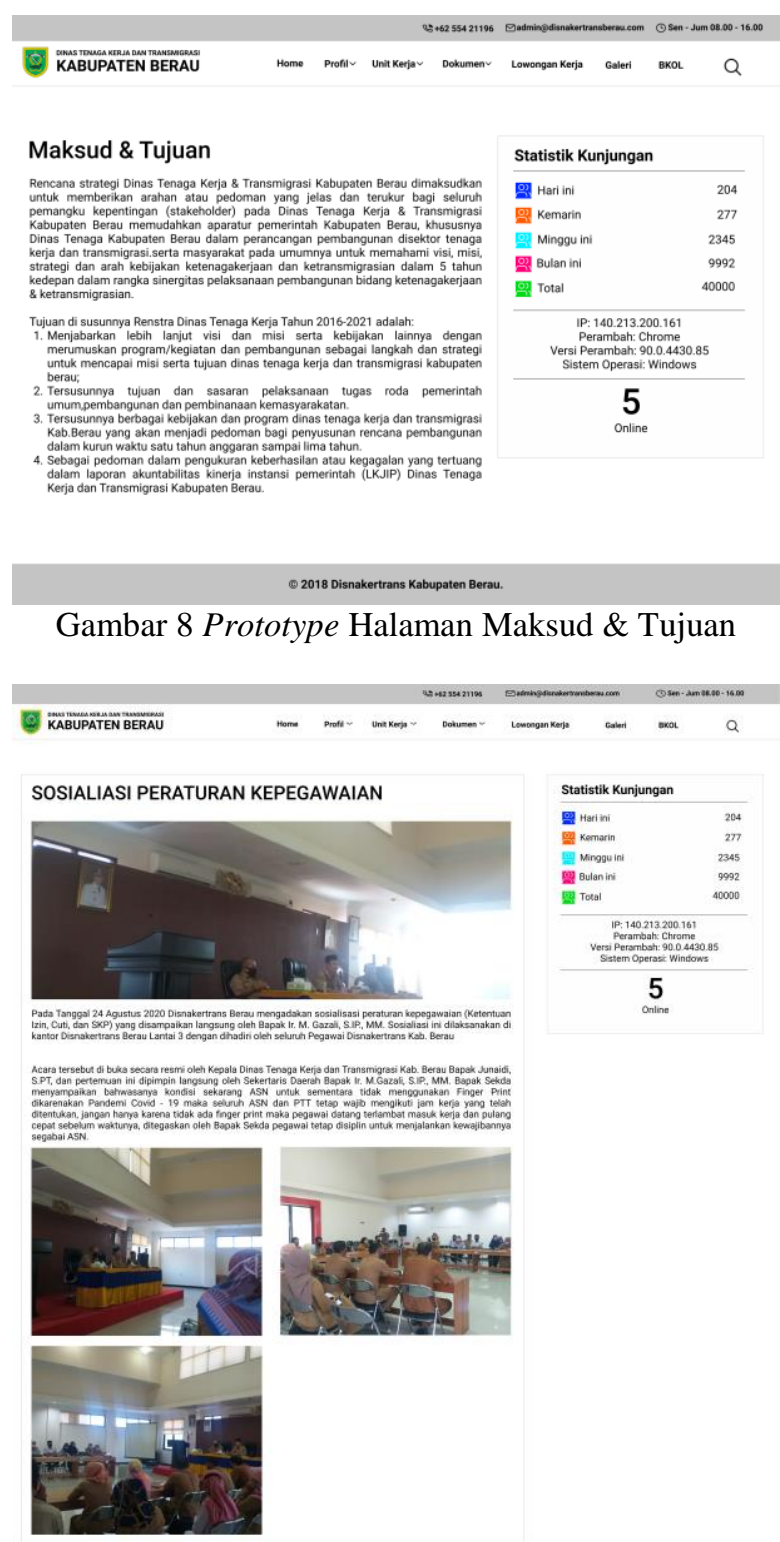

TUPOKS

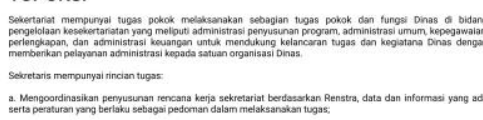

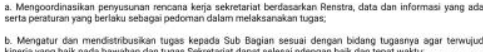

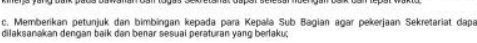

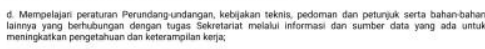

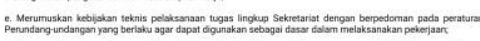

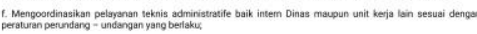

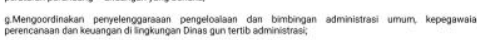

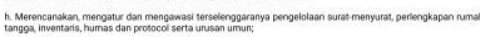

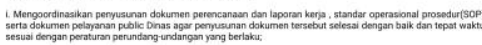

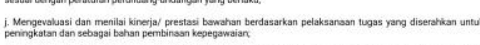

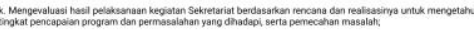

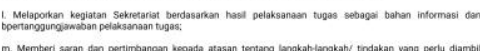

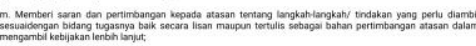

Gambar 9 Prototype Halaman Sosialisasi Peraturan Kepegawaian 


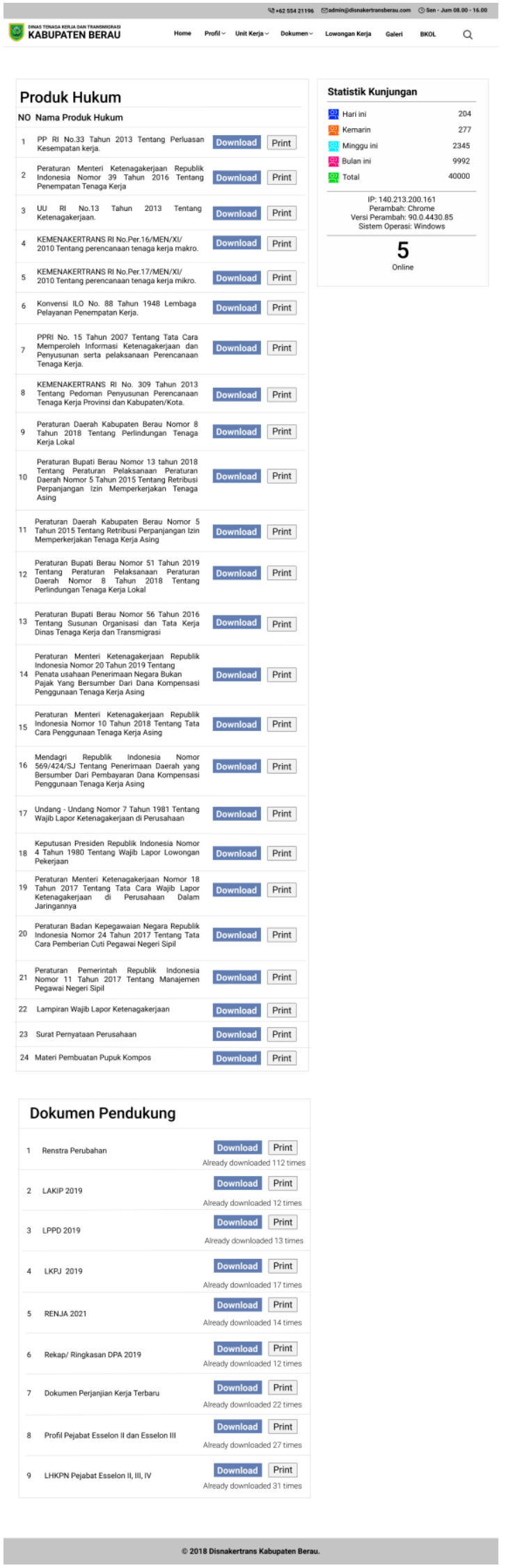

Gambar 10 Prototype Halaman Dokumen

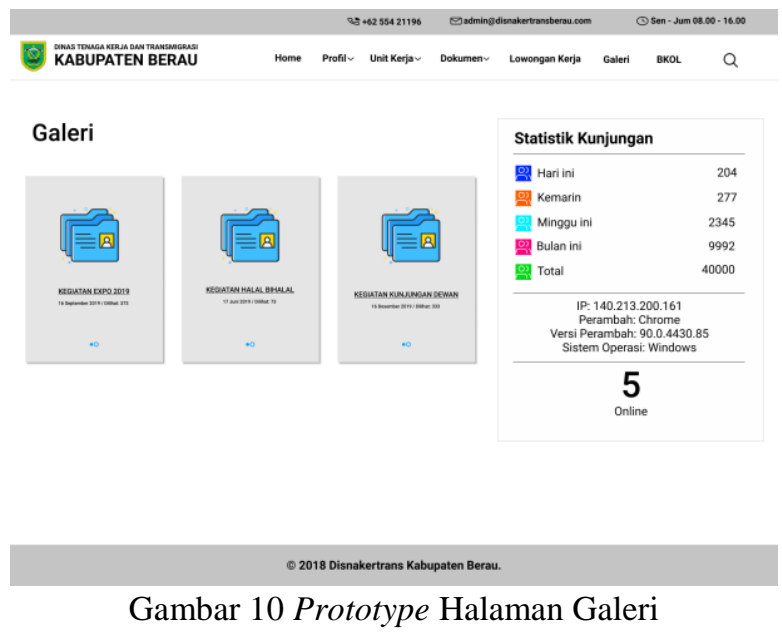

\section{KESIMPULAN}

Berdasarkan hasil penpenelitian dan hasil analisis data yang telah di lakukan dengan usability pada website Disnakertrans Kabupaten XYZ dapat di simpulkan sebagai berikut.

Didapatkan hasil dari usability testing Disnakertrans Kabupaten XYZ dengan menggunakan sebanyak 10 task yang di berikan kepada 8 responden secara acak adalah, dari total $100 \%$ responden yang ada, hanya terdapat sebanyak $62,5 \%$ responden yang dapat mengerjakan task 10 dan sebanyak $87,5 \%$ responden yang dapat mengerjakan task 7. Dari proses pengerjaan task scenario yang di lakukan responden, terdapat sebanyak 6 respon negatif yang di berikan responden pada fitur atau halaman website yang berbeda dimana respon negatif tersebut terdapat pada task 3, task 5, task 6, task 7, task 8, dan task 10. Selain itu, responden juga di minta untuk memberikan saran perbaikan (jika ada) seluruh responden memberikan saran perbaikan pada halaman berbeda yang terdapat pada task 2, task 3 , task 3, task 6, task 7 dan task 8 .

Rekomendasi perbaikan website Disnakertrans Kabupaten XYZ yaitu pada halaman home dilakukan perbaikan pada header dan footer dengan mengubah warna header serta menambah ukuran text selain meletakan bagian copyright di tengah pada footer dan menambahkan keseluruhan fitur search pada keseluruhan halaman. Selanjutnya adalah halaman maksud \& tujuan dilakukan pengubahan font pada penulisan artikel di halaman tersebut. Lalu pada halaman sosialisasi peraturan yang di kepegawaian, dilakukan perbaikan pada paragraf penulisan artikel. Pada halaman dokumen merupakan penggabungan dari halaman download dan halaman produk hukum dan merapikan bagian button agar mudah di jangkau oleh user dan perbaikan yang dilakukan pada Halaman galeri adalah dengan merapikan folder galeri serta memberikan keterangan disetiap foto pada folder galeri yang tersedia. 


\section{DAFTAR PUSTAKA}

[1] N. I. d. K. Liliek Budiastuti Wiratmo, "WEBSITE PEMERINTAH DAERAH SEBAGAI SARANA ONLINE PUBLIC RELATION," Jurnal ASPIKOM, vol. 3, no. 2, p. 236, 2017.

[2] S. J. Kuryanti, "RANCANGAN APLIKASI PENGAJUAN KARTU KUNING SECARA ONLINE (STUDI KASUS : DINAS TENAGA KERJA DAN TRANSMIGRASI KABUPATEN MUSI RAWAS)," Seminar Nasional Inovasi dan Tren (SNIT), p. 33, 2015.

[3] N. Huda, "IMPLEMENTASI METODE USABILITY TESTING DENGAN SYSTEM USABILITY SCALE DALAM PENILAIAN WEBSITE RS SILOAM PALEMBANG," Kumpulan jurnaL Ilmu Komputer (KLIK), vol. 06, p. 37, 2019.

[4] W. A. K. F. A. Indra Astuti, "ANALISIS USABILITYHOMEPAGE SITUS WEB PERPUSTAKAAN NASIONAL RI MENGGUNAKAN METODE THINKALOUD," Jurnal Pustakawan Indonesia, vol. 15, no. 12, p. 40, 2014.

[5] I. K. R. A. K. A. Tifani Yuliyana, "Usability Testing Pada Aplikasi POTWIS," Jurnal Sains dan Teknologi, vol. 8, no. 1, p. 14, 2019.

[6] J. Nielsen, "Usability 101: Introduction to Usability," 2012. [Online]. Available: https://www.nngroup.com/articles/usability-101introduction-to-usability/. [Accessed 3003 2021].

[7] J. Nielsen, Usability Engineering., Boston: Academic Press Inc., 2013.

[8] N. K. A. W. I. K. A. P. Ni Luh Putri Ari Wedayanti, "Evaluasi Aspek Usability pada Aplikasi Simalu Menggunakan Metode Usability Testing," MERPATI, vol. 7, no. 2, p. 117, 2019.

[9] H. H. B. P. Aisyah Sriwulandari, "Analisis dan Evaluasi Aspek Usability Pada Web HRMIS Telkom University Menggunakan Usability Testing," e-Proceeding of Engineering, vol. 1, p. 539, 2014.
[10] L. Rahmi, "Evaluasi Usability Fitur Webshare Pada Aplikasi Share it Menggunakan Metode Thinking-Aloud," ULTIMA, vol. X, no. 2, p. 112, 2019.

[11] J. Nielsen, Usability Engineering, New York: Academic Press, 1993.

[12] Jaspers, A Comparison of Usability Methods for Testing Interactive Health Technologies: Methodological Aspects and Empirical Evidence, International Journal of Medical Informatics, 2009.

[13] M. Suhartanto, "Pembuatan Website Sekolah Menengah Pertama Negeri 3 Delanggu," Journal Speed - Sentra Penelitian Engineering dan Edukasi, vol. 4, no. 1, p. 2, 2012.

[14] W. A. K. F. A. Indra Astuti, ANALISIS USABILITYHOMEPAGE SITUS WEB PERPUSTAKAAN NASIONAL RI MENGGUNAKAN METODE THINKALOUD, Bogor: Institut Pertanian Bogor, 2016. 